\title{
Best Article Award: Ahmad and Fanelli
}

\author{
Katherine S. Virgo ${ }^{1}$
}

Published online: 16 March 2016

(C) International Atlantic Economic Society 2016

The Atlantic Economic Journal is proud to announce that the winners of the Best Article Award are Ahmad H. Ahmad, Loughborough University, and his co-author, Suling Fanelli, University of Bath. Their paper entitled, "Fiscal Sustainability in the Eurozone: Is There a Role for Eurobonds," appeared in the September 2014 issue of the AEJ. A distinguished committee reviewed all eligible papers published in the same year. The committee was chaired by IAES Vice President Joel Mokyr, Robert H. Strotz Professor of Arts and Sciences and Professor of Economics and History at Northwestern University. Members of the committee included the AEJ Board of Editors and IAES Endowment Fund sponsors. The Managing Editor gratefully acknowledges the participation and diligence of all committee members who participated in the review process. The award emphasizes the intellectual and scholarly approach to economic research which has always been a focal point of the AEJ.

In light of the sovereign debt crisis originating in Greece and spreading to include core Eurozone countries, this unique paper assesses the fiscal sustainability of ten Eurozone member countries at a national and aggregate level. In addition, the authors evaluate whether or not the suggested fiscal consolidation of the Eurozone countries' national debts is a viable, long-term solution to the crisis. The work is based on the literature with respect to monetary unions and the framework of the European Monetary Union relative to the current sovereign debt crisis. Since Eurobonds were considered a viable solution to the crisis, yet had been largely overlooked in the literature, their impact on fiscal sustainability was empirically tested for the individual countries as well as for the entire Eurozone. Data sources included the Organization for Economic Coordination and Development (OECD) National Accounts Database, the Eurostat Database and the International Monetary Fund's International Financial Statistics Database.

The authors report that only three core Eurozone countries (Germany, Finland and Austria) exhibited characteristics of medium- and short-run fiscal sustainability.

Katherine S. Virgo

kvirgo@emory.edu

1 Emory University, Atlanta, GA 30322, USA 
The Netherlands, France, Spain, Portugal and Ireland were found to be only weakly sustainable. Without changes in fiscal and structural policies, these countries' positions were predicted to deteriorate. Italy and Belgium, on the other hand, were found to be structurally unsustainable due to the large accumulated stock of debt. Italy's situation was highlighted as more urgent than that of Belgium. The authors suggest the need for drastic action to decrease the stock of debt in the short run, while the countries continue to pursue critical economic reforms for long-run sustainability.

Overall, the authors find that adopting Eurobonds will greatly improve fiscal sustainability for the Eurozone countries, but the results are sensitive to the interest rate used. Empirical evidence supports the view that consolidating the national debts of the Eurozone countries will help to address the fiscal sustainability issue faced by the Eurozone as a whole. Suggested areas for future research include application of the analytic framework to non-Eurozone countries or to the CFA zones of West and Central Africa, as well as expanding the analytic framework to include factors such as the public finance impact of an aging population. 